\title{
PRIMENA KONCEPTA ELEKTRONSKE TRGOVINE U SRBIJI
}

\author{
Dragana Petrović \\ Visoka škola strukovnih studija informacionih tehnologija, Beograd
}

modernom poslovnom svetu se većina poslovnih transakcija obavljaju pomoću informaciono-komunikacionih tehnologija, uz čiju primenu se realizuju procesi elektronskog poslovanja i elektronske trgovine. Elektronsko poslovanje podrazumeva vršenje određenih transakcija putem mreže, najčešće Interneta. Elektronska trgovina, kao najznačajniji deo elektronskog poslovanja uključuje vršenje poslovnih transakcija a to su kupovina, prodaja, transfer ili razmena proizvoda putem računarskih mreža. Iz dana u dan ovaj vid trgovine se razvijao i postao multidisciplinarni koncept koji omogućuje automatizaciju poslovnih transakcija pomoću informaciono-komunikacione tehnologije. Rad će se baviti pojmom elektronskog poslovanja i elektronske trgovine, kao i razvojem elektronske trgovine na tržištu Srbije.

Ključne reči: elektronsko poslovanje, elektronska trgovina, Internet, Srbija, mreža

Uvod

U savremenom poslovnom okruženju je nemoguće da preduzeća posluju bez korišćenja informaciono-komunikacionih tehnologija jer su one obezbedile efikasan način vršenja poslovnih transakcija i visok stepen razmene informacija. Između učesnika u poslovnim transakcijama koji se nalaze na velikim geografskim udaljenostima i vremenskim razlikama, komunikacija je postala znatno brža. Tome je doprineo razvoj Interneta koji predstavlja mrežu svih mreža i označava početak jednog novog digitalnog doba. U poslovnom svetu je došlo do razvoja kompanija koje celo svoje poslovanje obavljaju na internetu, kao što su: Amazon, Google, Yahoo. Ove kompanije danas predstavljaju vodeće svetske ekonomske gigante, a pre tridesetak godina nisu ni postojale.

Elektronsko poslovanje je proces koji se realizuje putem računarske mreže, Ono je širi pojam od pojma elektronske trgovine jer pokriva sve oblasti života poslovnih subjekata i pojedinca kao što su: e-bankarstvo, e-uprava, e-zdravstvo, e-učenje i e-trgovina. Cilj ovog koncepta je efikasnije i brže vršenje poslovnih transakcija, kao i organizacija poslovanja u mrežnom okruženju.

* dr Dragana Petrović je profesor strukovnih studija. 
Elektronska trgovina (E-commerce) predstavlja upravljanje finansijskim transakcijama putem Internet mreže. To je sastavni deo elektronskog poslovanja koji je pomoću informaciono-komunikanikacionih tehnologija doživeo ekspanziju i dalje ostvaruje konstantnan rast. Elektronska trgovina kao mulitidisciplinarni koncept je prvo obuhvatao vršenje poslovnih transakcija pomoću EDI (Electronic Data Interchange) tehnologije koja predstavlja elektronsku razmenu podataka. Tu se misli pre svega na slanje poslovnih dokumenta od strane poslovnih subjekata (fakture, narudžbenice sl).

Nastanak Interneta je doprineo razvoju elektronske trgovine jer se na brz i jednostavan način dolazi do željenog proizvoda ili usluge. Pojavom elektronskih prodavnica razvilo se online tržište koje nema granica, tj. došlo je do prevazilaženja vremenskih, prostornih, jezičkih valutnih ograničenja.

Međutim činjenica da je upravo zbog nepostojanja granica, Internet dostupan svima i u bilo koje vreme, zbog čega je izložen ugrožavanju sigurnosti i krađi podataka, tako da je problem za elektronsko poslovanje i elektronsku trgovinu bezbednost transakcija. Kako tehnologija napreduje pronalaze se nova rešenja koja će obezbediti najveću moguću sigurnost zaštiti ovih podataka.

\section{Elektronsko poslovanje}

Elektronsko poslovanje (E-business) je prva uvela u upotrebu američka kompanija IBM koja se bavi računarskim tehnologijama, tj. proizvodnjom računarskog softvera, hardvera i poseduje najveći broj izuma u ovoj oblasti. Nastalo je 90 -ih godina prošlog veka pojavom sa elektronskih novčanih transfera - EFT (Electronic Fund Transfer) i EDI (Electronic Data Interchange) koje su banke pomoću privatnih mreža. Do ekspanzije elektronskog poslovanja je došlo razvojem Interneta, znači početkom XXI veka. Elektronsko poslovanje je vršenje poslovnih procesa pomoću računarske mreže koja omogućava brzo slanje velikog broja informacija između fizičkih i pravnih lica. Podaci koji se šalju su u elektronskom obliku pomoću sredstava elektronske komunikacije i elektronske obrade podataka.

Izraz elektronsko poslovanje ne podrazumeva samo kupovinu i prodaju robe, već predstavlja vršenje svih poslovnih transakcija primenom informaciono-komunikacione tehnologije (ICT-Information Communitacion Technology). To integralna komponenta koja u obuhvata vršenje poslovnih transakcija u svim sferama privredne aktivnosti jedne države (javna uprava, učenje, zdravstvo, trgovina, bankarstvo). Može se slobodno reći da je to globalna privredna aktivnost koja ne poznaje nacionalne granice i omogućuje efikasnost poslovnih transakcija putem savremenim komunikacionih mreža (Internet, Eksternet, Intranet).

Sa pojavom WWW-a elektronsko poslovanje doživljava novi uspon jer su time olakšani procesi razmene usluga, informacija i dobara putem Interneta. Elektronsko poslovanje podrazumeva digitalizaciju poslovnih transakcija koje napreduje svakodnevno, tako da ono predstavlja jednu globalnu aktivnost. Komponente elektronskog poslovanja kao sistema su prikazane na slici 1. 


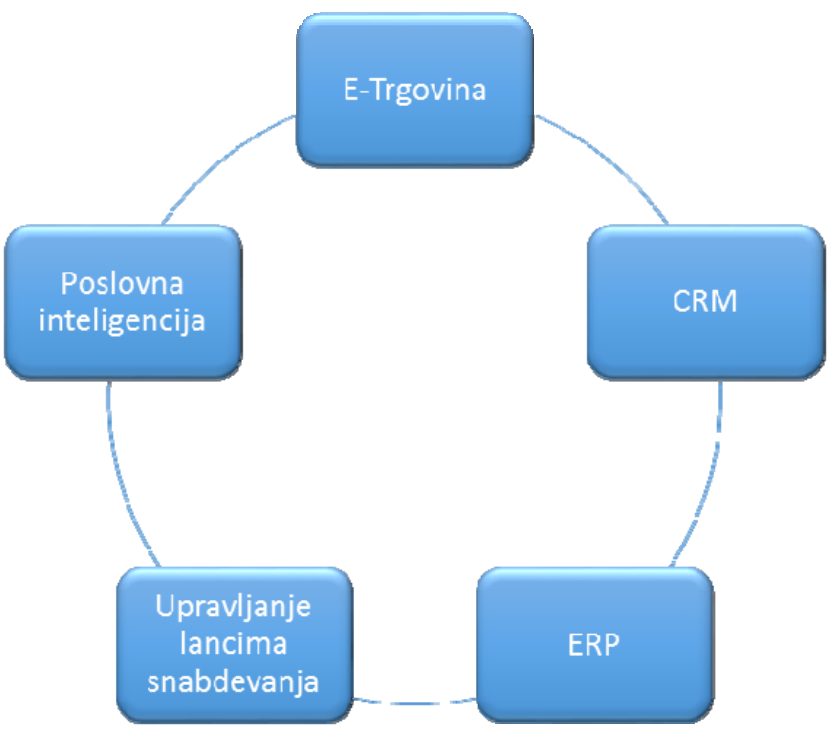

Slika 1 - Elektronsko poslovanje ${ }^{l}$

Elektronska trgovina kao jedan moderan koncept, podrazumeva korišćenje mreže radi obavljanja kupovine ili prodaje proizvoda i usluga. Ona se neprestano razvija i postala je multi disciplinaran koncept koji će biti objašnjen u narednom delu rada.

CRM (Customer Relationship Management) je složeni skup poslovnih procesa i tehnologija za unapređenje upravljanja odnosa sa postojećim i potencijalnim kupcima. Ovakva poslovna strategija ima za cilj smanjenje troškova poslovanja i povećanje prihoda putem prodaje proizvoda. Njegova suština se sastoji u analizi proizvoda koji kupac želi kupi, kako bi njihova prodaja od strane prodavca bila uspešna i ostvarilo jačanje lojalnosti klijenata.

ERP (Enterprise Resource Planning) predstavlja integrisanje i automatizaciju svih poslovnih procesa koji se odvijaju u kompaniji. Na taj način se softverski prati proizvodnja, finansije i logistika. Prednosti ERP sistema se sastoje u tome da postoji jedinstvena baza podataka u kojoj su svi podaci smešteni, tako da se smanjen napor za njihovo prikupljanje. Pored toga, ovaj sistem omogućava menadžmentu da brzo reaguje u nekim nepredviđenim situacijama i efektivno upravlja preduzećem. Najpoznatija ERP rešenja su: SAP, Oracle i Navision.

Upravljanje lancima vrednosti (SCM - Supply Chain Management) predstavlja sistem koji služi za praćenje toka dobara, informacija i novca od dobavljača preko proizvođača pa do krajnjeg kupca. Ovaj informacioni sistem povezuje dobavljače, proizvođače, prodavce na malo i krajnje korisnike. U situaciji kada dođe do nedostatka informacija o lancima isporuke, to može uzrokovati zastoj u razmeni dobara, novca i informacija, što dovodi do pojave gomilanja zaliha. Zbog toga je potrebno da se isporuka izvrši pravovremeno, kako bi se obezbedila just-in-time nabavka zaliha i repromaterijala i da bi troškovi bili minimalni.

\footnotetext{
${ }^{1}$ Simović V, Elektronsko poslovanje, skripta, Visoka škola strukovnih studija za IT-ITS, Beograd 2017, str. 9.
} 
Poslovna inteligencija (Business Intelligence - BI) je proces prikupljanja bitnih podataka iz internih i eksternih poslovnih procesa, da bi se na osnovu toga donele poslovne odluke. Savremene kompanije danas posluju u dinamičnom i promenljivom okruženju zbog čega su menadžmentu potrebne pouzdane informacije u procesu upravljanja i odlučivanja.

\section{Elektronska trgovina}

Elektronska trgovina (e-trgovina, e-commerce) kao sastavni deo elektronskog poslovanja (e-biznisa) predstavlja multidisciplinarni concept koji obuhvata kupovinu prodaju proizvoda i usluga pomoću savremenih informaciono-komunikacionih tehnologija. To predstavlja užu definiciju ovog koncepta. U širem smislu, ona obuhvata sve pretprodajne i postprodajne transakcije koje se odvijaju u lancu snabdevanja putem kompjuterskih mreža. Na osnovu toga, zaključujemo da je postojanje jedne kompanije na mreži nezaoblazan uslov da bi opstala na tržištu.

Da bi trgovina na Internet tržištu bila uspešna, potrebno je da kompanija poseduje opremu, informaciono obučene kadrove, informaciono komunikacione tehnologije, da poznaje zakone koji ga regulišu i da poznaje tehnološke aspekte tržišta.

U elektronskoj trgovini svaki Internet korisnik može da bude kupac jer pomoću Interneta može da odabere, poruči i plati proizvod ili uslugu i to 24 sata dnevno, tj. svih 7 dana u nedelji. Ona ne poznaje vremenske, jezičke, geografske i valutne granice Poenta je u jednostavnosti funkcionisanja koncepta, kao i niskim troškovima, zbog čega se smatra jednim od najprofitabilnijih oblika trgovine. Najpoznatije kompanije na Internetu su kompanije koje su postale veliki ekonomski giganti I koji doživljaju najbrži procvat. To su sledeće kompanije: Amazon, Aliexpress i Ebay. Njihovi sajtovi su uvek dostupni i katalozi omogućavaju kupcima kupe njihove proizvod bez ikakvih ograničenja iako su te kompanije hiljadama kilometara udaljene.

Najveća prednost elektronske trgovine jeste uvođenje automatizacije svih poslovnih procesa, što je dovelo da efikasnije poslovne saradnje i smanjenja troškova. Ona je uvela velike promene u odnosu na klasičnu trgovinu u pogledu brzine i fleksibilnosti, jer se sada sve transakcije brže odvijaju i podložnije su prilagođavanju promenama u savremenom poslovanju.

U savremenom digitalnom dobu se sve zasniva na informaciji, tako da trgovci nastoje da imaju što više informacija o kupcima kako bi saznali njihove želje, ponudu prilagodili njima, a njihova prodaja bila efikasnija. Pored toga, kompanije biraju snabdevače bez obzira na njihovo geografsko poreklo kako bi prodavala svoje proizvode i usluge na globalnom nivou. Stvaraju se potpuno nova tržišta.

Neke od osnovnih prednosti elektronske trgovine su da se ukida posrednik, jer kupac može direktno da vrši kupovinu. Pre nastanka elektronske trgovine su postojali tradicionalni trgovinski posrednici-maloprodaja i veleprodaja (prodaja proizvoda) i distributeri (prodaja usluga). Njihovu ulogu su danas preuzeli nova vrsta posrednika, a to su softver $\mathrm{i}$ hardver koji predstavljaju neophodne elemente u realizaciji elektronske trgovine.

\footnotetext{
${ }^{2}$ Vulić M, Elektronska trgovina, Visoka škola strukovnih studija za IT-ITS, Beograd 2015, str. 15.
} 
Prednosti elektronske trgovine za krajnjeg kupca su da može proizvod da kupi iz fotelje u bilo kom delu sveta, kao i da dobija pregledne interaktivne multimedijalne kataloge sa mnoštvo informacija. Prednosti elektronske trgovine za prodavca se sastoje u tome da su cene proizvoda prilagodljive i lako promenljive, nisu mu potrebni maloprodajni objekti i nekretnine i manje je papirologije.

Međutim elektronska trgovina ima i svoja ograničenja koja se sastoje u tome da u njoj nedostaje živi kontakt sa prodavcem što predstavlja ključan faktor u prodaji. Jedini vid komunikacije u vidu razmene utisaka i kritika između kupca i prodavca je putem mejla. Još neka od ograničenja elektronske trgovine su:

- Kupovina preko Interneta je ljudima i dalje nesigurna i potrebna je doza poverenja (sa obe strane),

- Mnogi ljudi još uvek ne koriste Internet u toj meri da bi isti taj Internet koristili za kupovinu,

- Ugrožena lična i finansijska privatnost ,

- Internet predstavlja javnu mrežu koja je dostupna svima i uvek postoji faktor zloupotrebe

U cilju očuvanja sigurnosti kupaca prodavaca, potrebno je uvesti sledeće bezbednosne mere:

- Autentičnost informacija (definisanje i provera identiteta pošiljaoca pomoću digitalnih potpisa i sertifikata koji potvrđuju autentičnost pošiljaoca i sadržaj njegove poruke)

- Zaštita tajnosti informacija,

- Integritet informacija (sprečavanje neovlašćene izmene informacija),

\section{Razvoj i značaj elektronske trgovine u Srbiji}

Na našim prostorima upotreba elektronskog poslovanja i elektronske trgovine je i dalje na samom početku, jer su neki aspekti zakonske regulative i još uvek prilagođeni tradicionalnom načinu poslovanja. Pored toga u mnogim državnim strukturama postoji nedostatak infrastrukture kako bi se pružile elektronske usluge u vršenju poslovnih transakcija. U odnosu na državni sektor, u kompanijama na našim prostorima papirnu dokumentaciju je u najvećem broju slučajeva zamenila elektronska, dok se najveći broj transakcija vrši putem Interneta.

Elektronska trgovina u Srbiji se razvija svakodnevno jer je na elektronskom tržištu dostupan veliki broj broj informacija koji neprestano raste. Građani Srbije trguju sve više putem Interneta tako da je sada moguće platiti računarsku opremu, belu tehniku, mobilne telefone, turističke aranžmane, avionske karte itd. Elektronska trgovina omogućava brži pronalazak željenog artikla, lakše upoređivanje cena i plaćanje transakcije bez odlaska banku, tj. putem dva klika na kompjuteru.

Na osnovu istraživanja u 2017 godini, u proseku je 41,4\% preduzeća naručivalo je tokom 2016. godine proizvode/usluge putem Interneta, a 23,8\% preduzeća primalo porudžbine putem Interneta. Kada sagledamo strukturu preduzeća prema veličini, dobijamo sledeće rezultate i to:

$-59,6 \%$ velikih preduzeća naručivalo je proizvode/usluge putem interneta;

- 46,5\% srednjih preduzeća naručivalo je proizvode/usluge putem interneta;

- 39,3\% malih preduzeća naručivalo je proizvode/usluge putem interneta.

Društvene mreže su sve prisutnije i u poslovanju preduzeća. U prilog tome govore rezultati istraživanja koji pokazuju da je $39,2 \%$ preduzeća koristilo neku od društvenih mreža za potrebe svog poslovanja. Pored toga, 9,3\% preduzeća plaća usluge klaud (cloud) servisa. 
U Republici Srbiji 99,7\% preduzeća ima internet priključak, veb-sajt poseduje 80,4\% preduzeća. Na sledećoj tabeli 1 dat je grafički prikaz korišćenja Interneta u poslovanju preduzeća (u \%).

Tabela 1 - Preduzeća koia koriste Internet u svom poslovaniu ${ }^{3}$

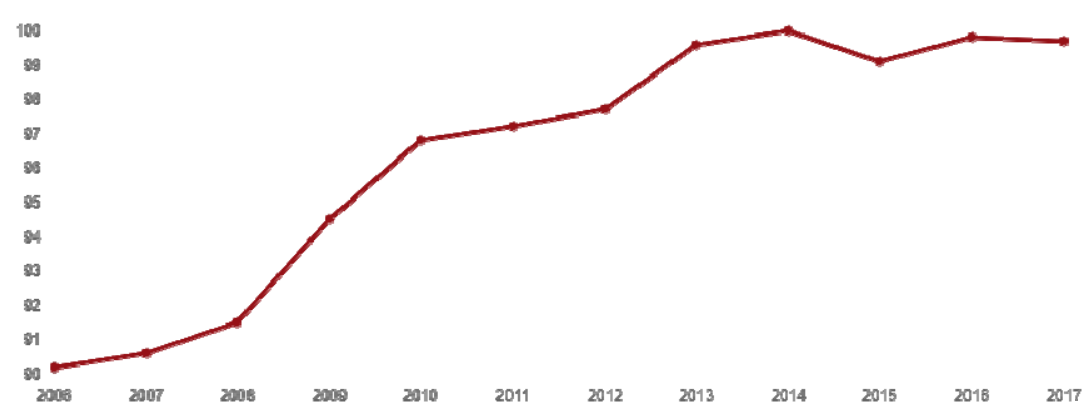

Na osnovu prikazanog se vidi da iz godine u godinu raste broj preduzeća koja koriste Internet, tako da se može reći i da raste korišćenje usluga elektronskog poslovanja i elektronske trgovine. Ipak vidimo da u 2015. godini dolazi do blagog pada, a nakon toga opet raste korišćenje Interneta.

U 2017. godini oko 68\% domaćinstava u Republici Srbiji poseduje Internet priključak. Zastupljenost internet priključka je najveća u Beogradu i iznosi 77,5\%. U Vojvodini ona iznosi $68,7 \%$, a u centralnoj Srbiji 63,8\%. Pored toga, oko 90,5\% domaćinstava poseduje mobilni telefon, $43,7 \%$ poseduju lap top, a $61,9 \%$ poseduje širokopojasnu internet konekciju, što je prikazano na tabeli 2.

Tabela 2 - Domaćinstva koja poseduju računar, Internet priključak i širokopojasnu Internet konekciju ${ }^{4}$

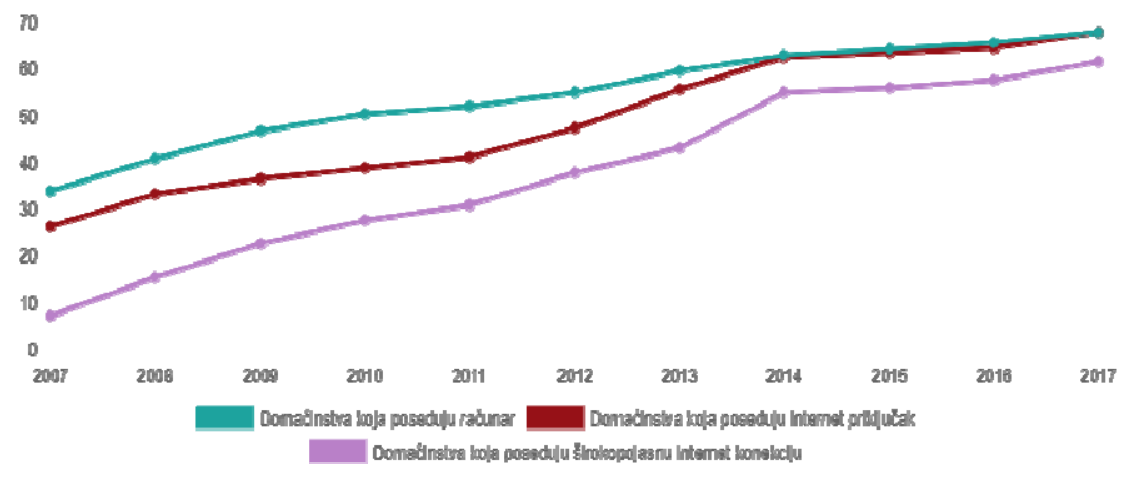

\footnotetext{
${ }^{3}$ Republički zavod za statistiku, Upotreba informaciono-komunikacionih tehnologija u Republici Srbiji, 2017. http://www.stat.gov.rs sr-latn/oblasti/upotreba-ikt/preduzeća

${ }^{4}$ Republički zavod za statistiku, Upotreba informaciono-komunikacionih tehnologija u Republici Srbiji , 2017. http://www.stat.gov.rs sr-latn/oblasti/upotreba-ikt/domaćinstva
} 
U Republici Srbiji u 2017. godini preko 3.300.000 lica koristi računar svakog ili skoro svakog dana. Oko 32\% internet populacije koristi usluge e-uprave. U poslednja 3 meseca je $28,3 \%$ korisnika interneta kupovalo/poručivalo robu ili usluge putem interneta. Procenat Internet populacije od 16-24 godina koja poseduje nalog na društvenim mrežama iznosi 90,6\%.

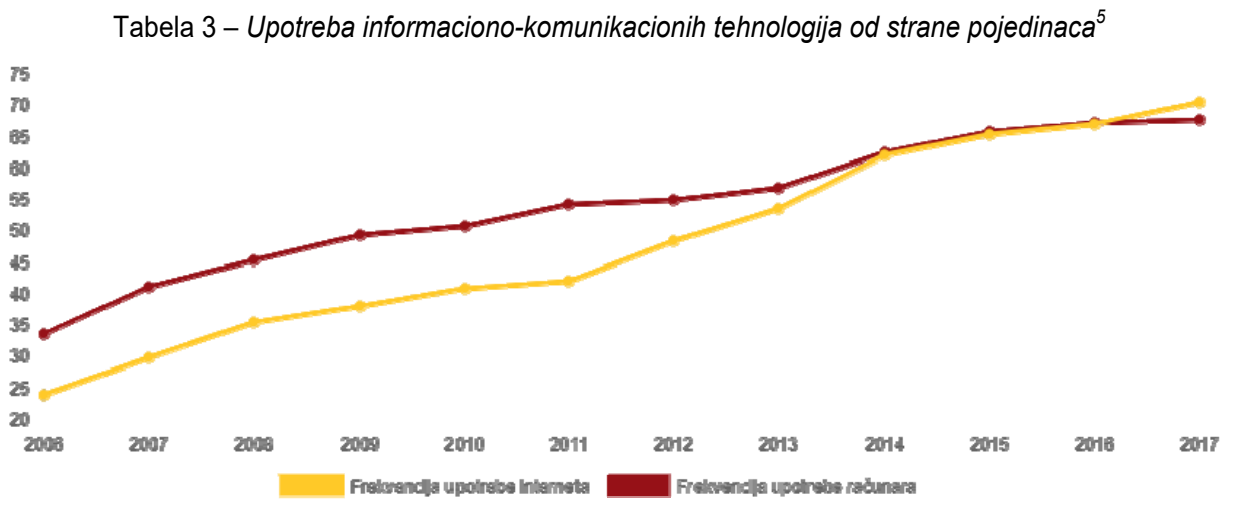

Iz prikazane tabele se vidi da iz godine u godinu raste frekvencija upotrebe Interneta i frekvencija upotrebe računara. Do 2014. je frekvencija upotrebe računara imala veći rast, međutim frekvencija upotrebe Interneta doživljava ekspanziju u 2016. godini i po rastu prevazilazi frekvenciju upotrebe računara od strane pojedinaca.

\section{Zaključak}

Elektronsko poslovanje predstavlja u današnje vreme obavljanje poslovnih procesa pomoću informacionih tehnologija. Ova vrsta tehnologije je dovela do ogromnog napretka u svetu jer je omogućeno da se efikasnije obavljaju zadaci, brzo razmenjuju informacije, ostvarivanje uštede u troškovima poslovanja bez obzira na vremensku i geografsku udaljenost. Sve to doprinosi da kompanije postaju moćnije i konkurentnije na tržištu.

Elektronska trgovina kao deo elektronskog poslovanja obuhvata sve kupoprodajne, ali i pretprodajne i postprodajne transakcije putem informaciono-komunikacionih tehnologija, prvenstveno Interneta. To je multidisciplinarni koncept jer obuhvata upravljanje lancem snabdevanja, transfer novca, e-marketing, kao i razmenu podataka i dokumenata. Ona predstavlja jedan od vodećih načina poslovanja u svetu koji je doživeo svoju ekspanziju i koji nastavlja dalje da se ubrzanim tempom razvija.

Na kraju, možemo zaključiti da su informacione tehnologije pojednostavile funkcionisanje kompanija, državnih institucija i sam život ljudi. Ipak, treba da imamo u vidu da upotreba elektronskog poslovanja u Srbiji i dalje nije na onom nivou kao što je to slučaj u razvijenim ekonomijama. Zbog nedovoljne edukacije građana na tom polju, oni se i dalje pribojavaju bezbednog i sigurnog plaćanja putem Interneta.

\footnotetext{
${ }^{5}$ Republički zavod za statistiku, Upotreba informaciono-komunikacionih tehnologija u Republici Srbiji , 2017. http://www.stat.gov.rs sr-latn/oblasti/upotreba-ikt/pojedinci
} 
Cilj je da elektronska trgovina postane deo savremenog života ljudi. Potrebno je da korisnici ovih usluga imaju niže cene, banke imaju niže troškove transakcija i budu produktivnije, kao i da trgovci imaju lakši pristup tržištu. Usvajanjem seta zakona kojima se uređuje elektronski potpis, elektronski pečat, elektronsko čuvanje dokumenta, razmena informacija i bezbednost u oblasti elektronske trgovine, ovaj savremen koncept u Srbiji tek treba da ostavi svoj pečat.

\section{Literatura}

[1] Simović V, Elektronsko poslovanje, Visoka škola strukovnih studija za IT-IST, Beograd 2016.

[2] Vulić M, Elektronska trgovina, Visoka škola strukovnih studija za IT-ITS, Beograd 2015.

[3] Jevremović S, Bezbednost elektronskog poslovanja, Visoka škola strukovnih studija za ITITS, Beograd 2014.

[4] Radenković B, Despotović-Zrakić M, Bogdanović Z, Barać D, Labus A, Elektronsko poslovanje, FON, Beograd, 2015.

[5] Unković M, Milosavljević M, Stanišić N., Elektronsko i berzansko poslovanje, Singidunum, Beograd, 2010.

[6] Zakon o platnim uslugama, SI. gl. RS 139/2014

[7] Zakon o elektronskom dokumentu, elektronskoj identifikaciji i uslugama od poverenja u elektronskom poslovanju, SI. gl RS 94/2017

[8] Vasković V, Sistemi plaćanja u eletronskom poslovanju, FON, Beograd, 2007.

[9] Stankić R, Elektronsko poslovanje, Ekonomski Fakultet, Beograd, 2009.

[10] Republički zavod za statistiku, Upotreba informacionih-komunikacionih tehnologija u Republici Srbiji, www.stat.gov.rs 